\title{
A SENSITIVITY ANALYSIS OF THE KEY PARAMETERS FOR THE PREDICTION OF THE PRESTRESS FORCE ON BONDED TENDONS
}

\author{
JUNG BUM JANG*, HONG PYO LEE, KYEONG MIN HWANG and YOUNG CHUL SONG \\ KEPCO Research Institute, 103-16, Munji-Dong, Yuseong-Gu, Daejeon 305-380, Korea \\ ${ }^{*}$ Corresponding author. E-mail : jbjang@kepri.re.kr
}

Received December 29, 2009

Accepted for Publication May 01, 2010

Bonded tendons have been used in reactor buildings at some operating nuclear power plants in Korea. Assessing prestress force on these bonded tendons has become an important pending problem in efforts to assure continued operation beyond their design life. The System Identification (SI) technique was thus developed to improve upon the existing indirect assessment technique for bonded tendons. As a first step, this study analyzed the sensitivity of the key parameters to prestress force, and then determined the optimal parameters for the SI technique.

A total of six scaled post-tensioned concrete beams with bonded tendons were manufactured. In order to investigate the correlation of the natural frequency and the displacement to prestress force, an impact test, a Single Input Multiple Output (SIMO) sine sweep test, and a bending test using an optical fiber sensor and compact displacement transducer were carried out.

These tests found that both the natural frequency and the displacement show a good correlation with prestress force and that both parameters are available for the SI technique to predict prestress force. However, displacements by the optical fiber sensor and compact displacement transducer were shown to be more sensitive than the natural frequency to prestress force. Such displacements are more useful than the natural frequency as an input parameter for the SI technique.

KEYWORDS : Bonded Tendon, Prestress Force, Natural Frequency, Displacement, Modal Test, Bending Test

\section{INTRODUCTION}

Bonded tendons have been used in reactor buildings of heavy water reactors and the light water reactors of some nuclear power plants operating in Korea. The assessment of prestress force on these bonded tendons is becoming an important issue in assuring their continuous operation beyond their design life. These bonded tendons are of a type in which cement grout fills the inside of the sheath pipe that goes around the tendon. Currently, Wolseong units Nos. 1, 2, 3, 4 and Uljin units Nos. 1, 2 have adopted bonded tendons [1]. The existing assessment of prestress force on bonded tendons is indirectly measured by using test beams manufactured at the time of construction and carrying out bending tests, fracture tests, and lift-off tests during in-service inspection [2]. Both the bending test and the fracture test are carried out on bonded test beams; the lift-off test is carried out on unbonded test beams because the lift-off test can't be applied to bonded tendons. However, these test beams have the limitation of indirect assessment because the actual stress acting on a bonded tendon in a reactor building cannot be replicated exactly. Wolseong unit No. 1, in particular, must go through a time-limited aging analysis in order to continue operating after 2012, and the single structure-related assessment item for this analysis is the assessment of prestress force on the bonded tendon. Therefore, the technology to quantitatively assess prestress force on bonded tendons currently installed in reactor buildings must be developed soon.

Numerous applications of non-destructive tests, such as an ultrasonic test and a pulsed eddy current test, have been used to evaluate prestress force on bonded and unbonded tendons. Such non-destructive tests have been shown to have several problems-for instance, weakened signal detection due to the use of concrete and grouting materials, and difficulties related to the installation of a sensor on the tendon embedded within the structure [3]. Thus, technology is being developed to analyze the loss of prestress force and to predict prestress force through the SI technique, which uses the dynamic characteristics, strain, or displacement of the structure according to the prestress force [4-11]. 
Hence, this study developed a prestress force assessment technique for bonded tendons using the SI technique in order to improve existing methods for assessing the prestress force on bonded tendons. As a first step, the influence of the important parameters of the SI technique when assessing prestress force was evaluated and the optimal parameters were derived for the SI technique.

\section{SCALE-MODEL TEST}

\subsection{Scale-model Specimens}

The results of examining the static and dynamic characteristics of the structure with the prestressing system show that the natural frequency and displacement of the structure were the most representative characteristics $[7,8,10,12]$. In other words, the largest change in natural frequency and displacement is expected when a change occurs in the magnitude of the prestress force on the bonded tendon in the reactor building. Therefore, natural frequency and displacement were selected as parameters to predict the prestress force of a bonded tendon.

In order to analyze the correlation between the prestress force of a bonded tendon and these parameters, scale-model specimens with the bonded tendon were manufactured. As shown in Fig. 1, a total of six scale-model specimens were manufactured that measured $8.0 \mathrm{~m}$ long and had a cross-sectional area of $0.09(0.3 \times 0.3 \mathrm{~m}) \mathrm{m}^{2}$. The concrete compressive strength of the scale-model specimen was 35.0 MPa; a load cell was installed on one end of the specimen to measure the prestress force induced on the specimen. Furthermore, four rebars with a diameter of $16 \mathrm{~mm}$ were installed longitudinally on the top and bottom of the specimen, and sixty rebars with a diameter of $10 \mathrm{~mm}$ were installed to fix the location of the sheath pipe where the grouting material surrounding the strands was injected. VSL Type P was used as the system to anchor the strands and three strands with a diameter of $15.2 \mathrm{~mm}$ were used to apply prestress force. The prestress forces applied to each scale- model specimen were determined considering the real prestress forces of the reactor building at the heavy water reactor and the magnitude of the prestress force

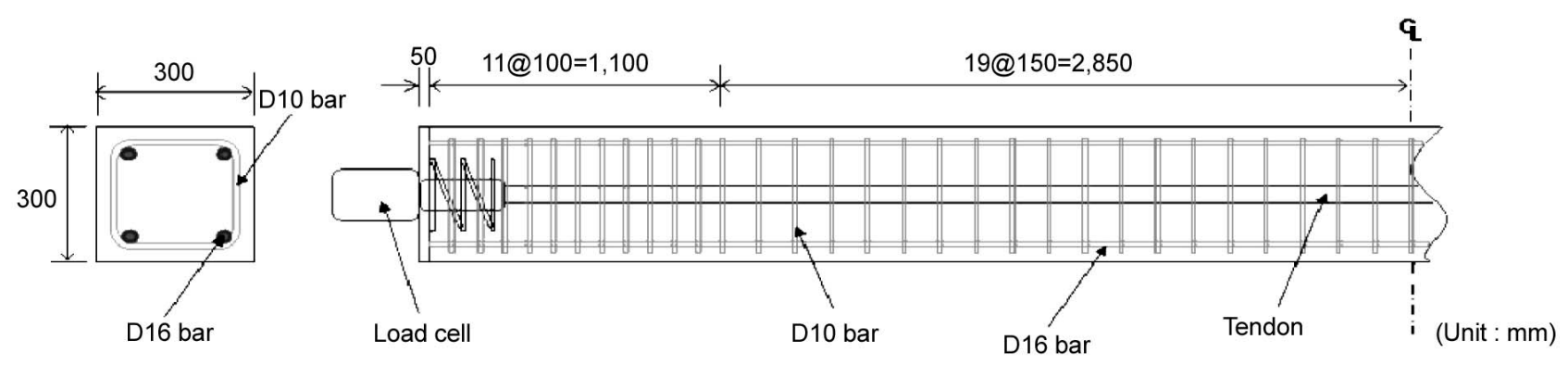

Fig. 1. Scale-model Specimen

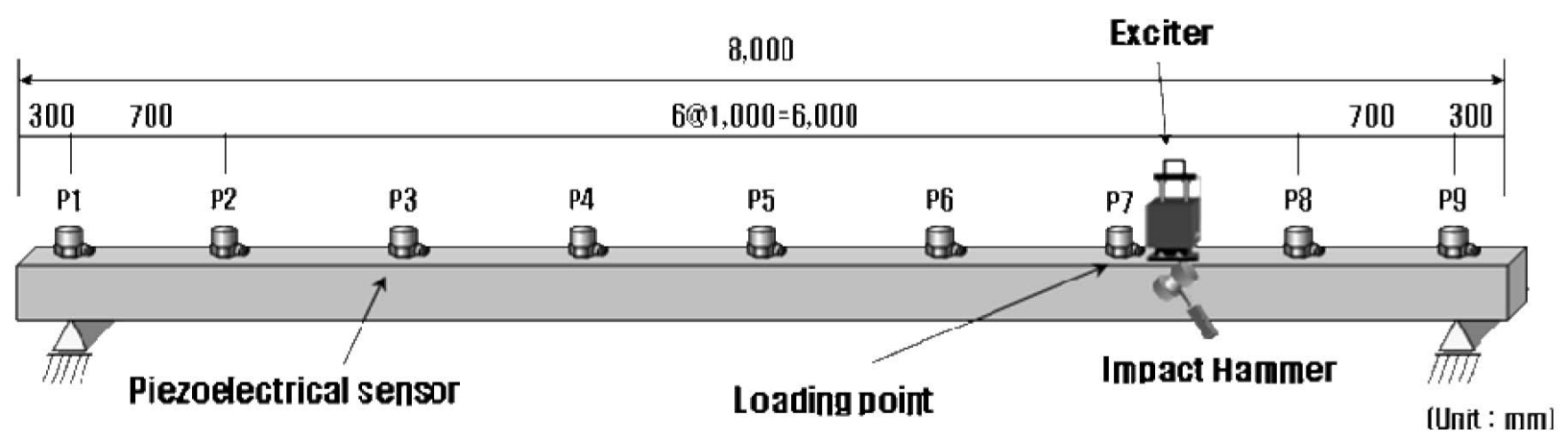

Fig. 2. Modal Test 
was adjusted according to the law of similarity. The prestress forces applied to each of the six scale-model specimens were $0 \mathrm{kN}, 146 \mathrm{kN}, 264 \mathrm{kN}, 356 \mathrm{kN}, 465 \mathrm{kN}$, and $523 \mathrm{kN}$, respectively. The prestress force of $465 \mathrm{kN}$ was the initial prestress force put on a real bonded tendon in a reactor building.

\subsection{Experimental Methods}

A modal test and a bending test were carried out to analyze the correlation of the natural frequency and the displacement to the prestress force of a bonded tendon. For natural frequency, an impact test and SIMO sine sweep test were carried out as the modal test; for displacement, bending tests using an Optical Fiber Sensor (OFS) and a Compact DisPlacement transducer (CDP) were carried out.

\subsubsection{Modal Test}

A modal test was carried out to analyze the correlation between prestress force and natural frequency. The impact test and SIMO sine sweep test were carried out as the modal test and nine accelerometers of the piezoelectrical type were installed on the specimen as shown in Fig. 2 to measure the acceleration response signals occurring during the test.

Load from an impact hammer and exciter were put on at P7 in Fig. 2 as based on the numerical modal analysis that was carried out beforehand to obtain a variety of mode shapes. The impact test was carried out five times on each specimen and the mean value was used. The frequency range of the impact hammer was $0 \sim 256 \mathrm{~Hz}$ and the magnitude of the impact load was about 2,500 N. The load of the exciter was $20 \mathrm{~N}$, the frequency ranged from 2 to
$150 \mathrm{~Hz}$, and the sweeping rate of frequency was $0.05 \mathrm{~Hz} / \mathrm{s}$.

\subsubsection{Bending Test \\ 2.2.2.1 Optical Fiber Sensor}

A bending test was carried out to analyze the correlation between prestress force and displacement. An optical fiber sensor was installed on the scale-model specimen to measure displacement. An optical fiber sensor was employed in this study because it is not affected by electromagnetic noise and is more precise than existing electrical sensors. Also, it can be installed without causing harm to the structure because it is small and light.

The optical fiber sensor used in this paper was made with the FBG (Fiber Bragg Grating). For the main characteristics of the optical fiber sensor, the center wavelength was $1,550 \mathrm{~nm}$ and the length of the FBG sensor was $20 \mathrm{~mm}$. In order to analyze the reliability of the displacement measured by the optical fiber sensor, two sets of optical fiber sensors were installed parallel to one another on the specimen and temperature sensors were installed at both ends for temperature compensation as illustrated in Fig. 3. The load was applied to the center of the specimen; its magnitude ranged from $9.8 \mathrm{kN}$ to $24.5 \mathrm{kN}$.

\subsubsection{Compact Displacement Transducer}

Seven compact displacement transducers were installed on the bottom of the scale-model specimen at a uniform interval of $1.0 \mathrm{~m}$ and bending tests were carried out to analyze the correlation between prestress force and displacement like the optical fiber sensor. Loading point and magnitude were the same as those of the optical fiber sensor.

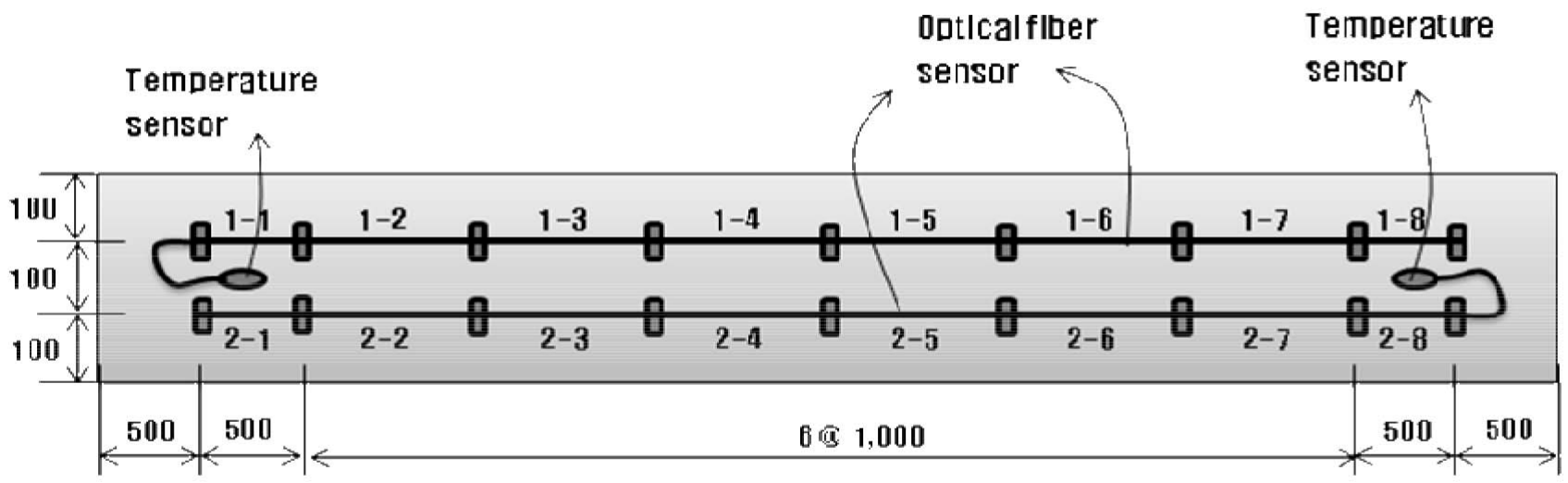

Fig. 3. Installation Scheme of the Optical Fiber Sensor 


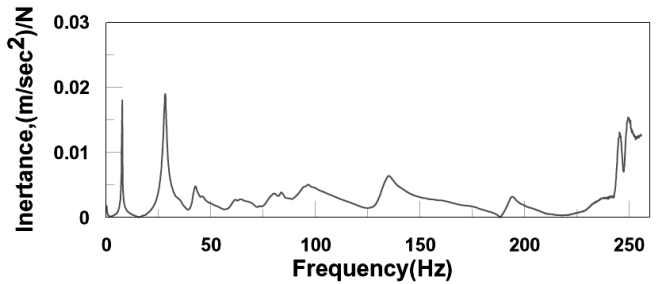

(a) $0 \mathrm{kN}$

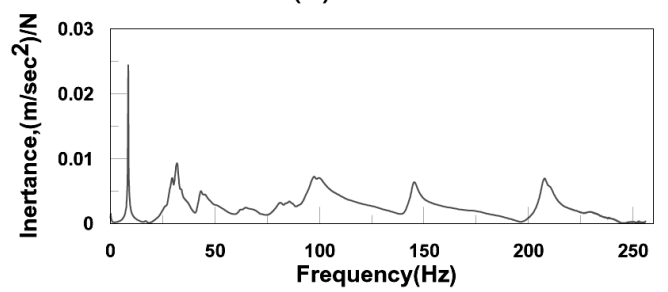

(c) $264 \mathrm{kN}$

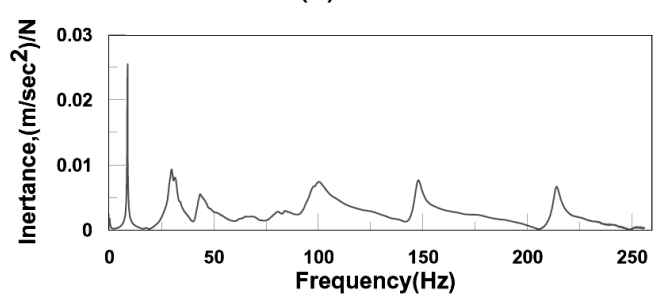

(e) $465 \mathrm{kN}$

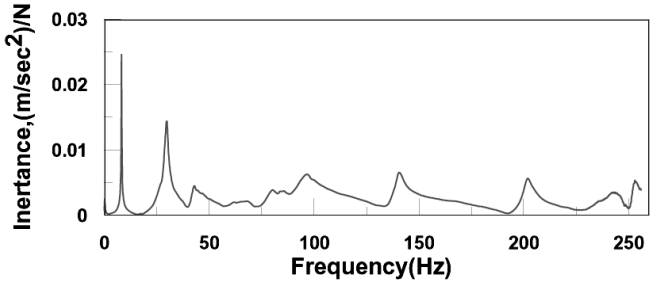

(b) $146 \mathrm{kN}$

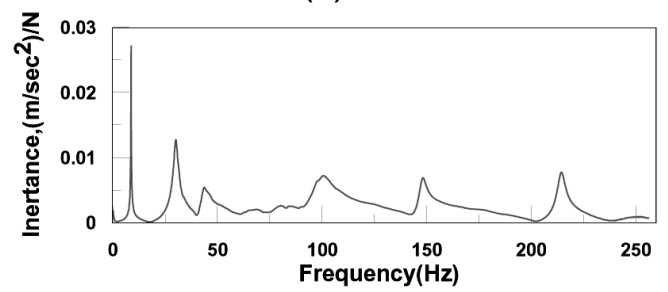

(d) $356 \mathrm{kN}$

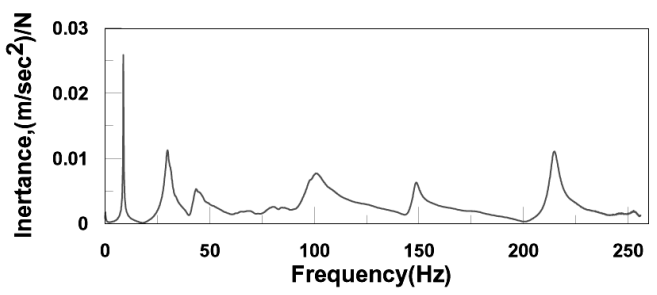

(f) $523 \mathrm{kN}$

Fig. 4. Frequency Response Function of the Impact Test

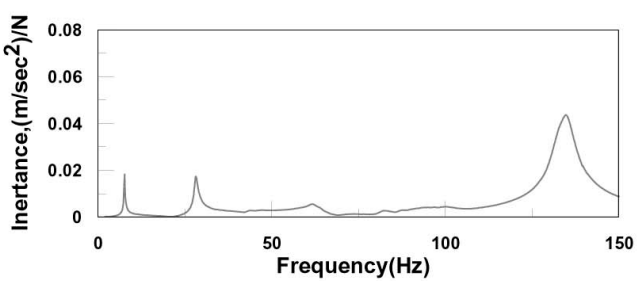

(a) $0 \mathrm{kN}$

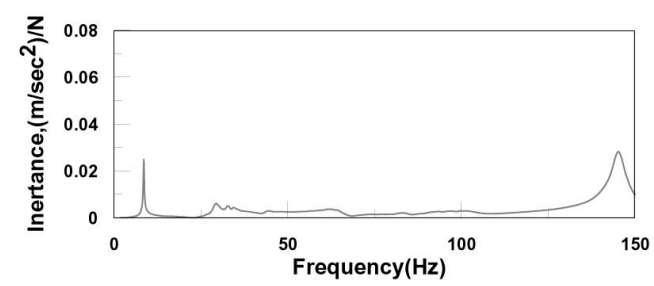

(c) $264 \mathrm{kN}$

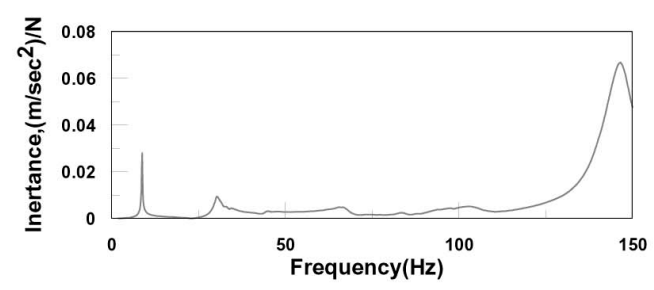

(e) $465 \mathrm{kN}$

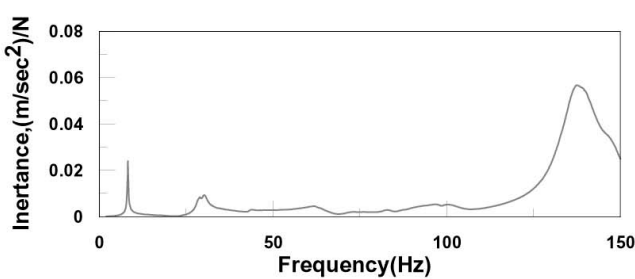

(b) $146 \mathrm{kN}$

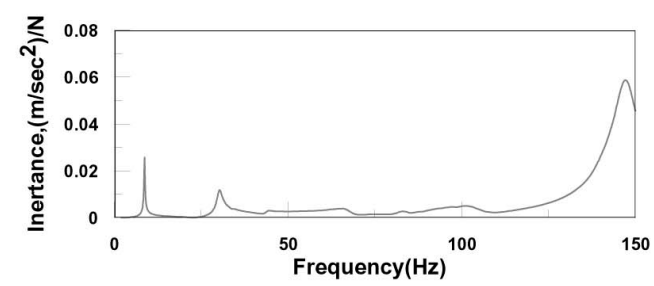

(d) $356 \mathrm{kN}$

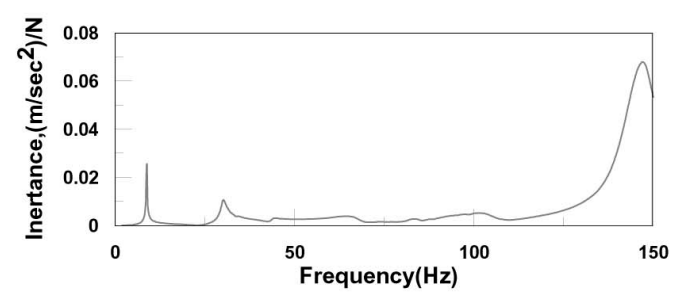

(f) $523 \mathrm{kN}$

Fig. 5. Frequency Response Function of SIMO Sine Sweep Test 


\section{EXPERIMENTAL RESULTS}

\subsection{Modal Test}

The test results are shown in Fig. 4 for the impact test and Fig. 5 for the SIMO sine sweep test. They show the frequency response function that analyzed the acceleration response signal, which occurred on the six scale-model

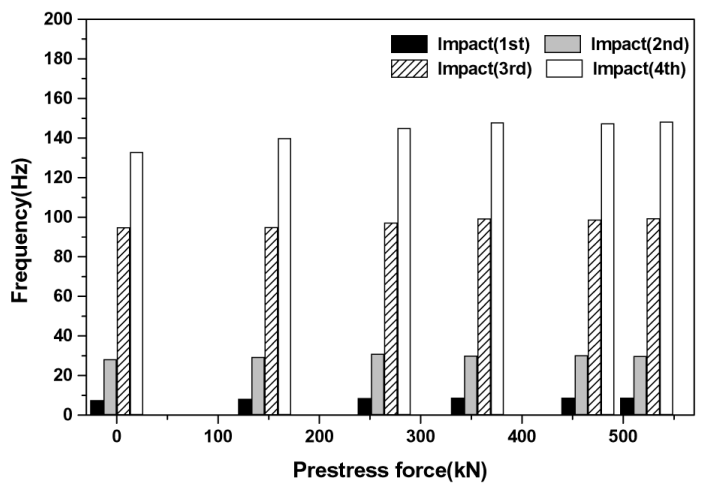

(a) Impact test

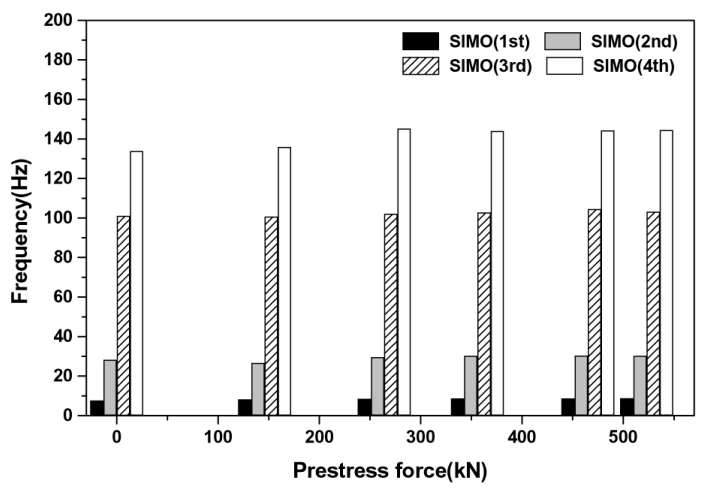

(b) SIMO sine sweep test

Fig. 6. Natural Frequency vs. Prestress Force

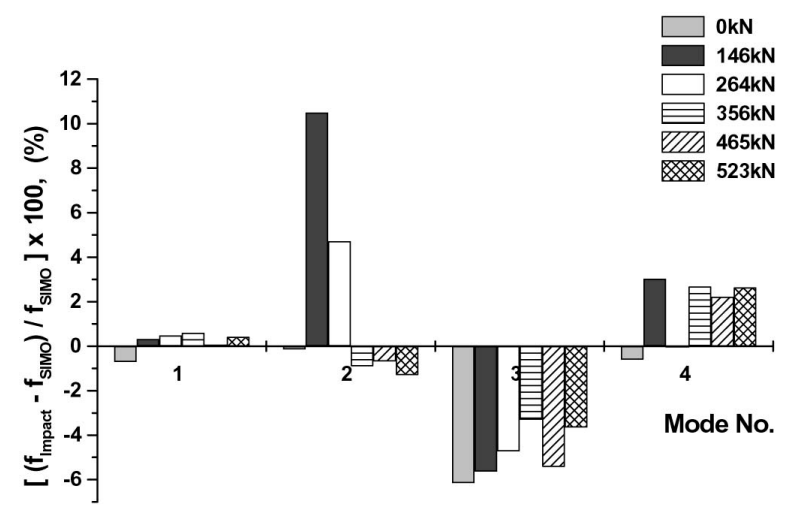

Fig. 7. Comparison Between Impact Test and SIMO Sine Sweep Test specimens. The total weighted least square complex frequency domain was adopted as a modal parameter extraction technique. Figure 6 presents the natural frequency of each mode according to the prestress force by the impact test and SIMO sine sweep test. It can be observed in both test results that as prestress force increases, natural frequency also proportionally increases.

In order to analyze the reliability of the natural frequencies measured using the impact test and the SIMO sine sweep test, natural frequencies obtained through the two tests were compared as shown in Fig. 7 . $\mathrm{f}_{\text {Impact }}$ is the natural frequency by the impact test and $\mathrm{f}_{\text {SIMo }}$ is the natural frequency by the SIMO sine sweep test in Fig. 7. As indicated in Fig. 7, the difference ratios of the natural frequencies measured by both the impact test and SIMO sine sweep test are a maximum of $0.7 \%$ for the $1^{\text {st }}$ mode, $10.5 \%$ for the $2^{\text {nd }}$ mode, $-6.2 \%$ for the $3^{\text {rd }}$ mode and 3.0 $\%$ for the $4^{\text {th }}$ mode, and the two test results were very similar. Thus, the natural frequencies obtained by the two test methods are highly reliable.

Figure 8 shows the change rate in natural frequency according to prestress force, where change rate means the

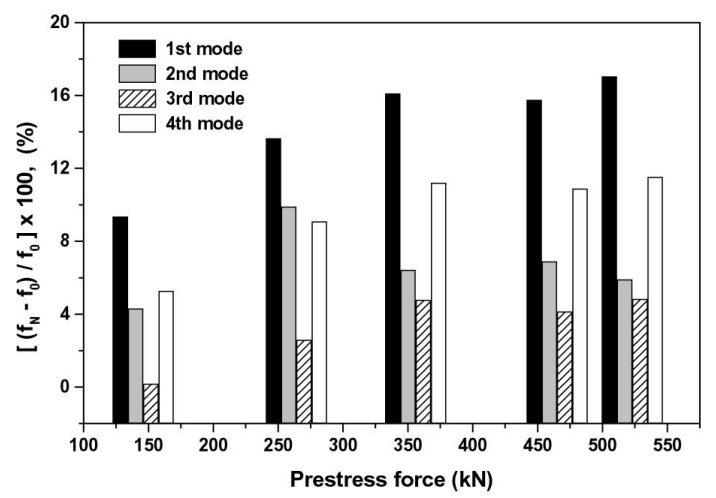

(a) Impact test

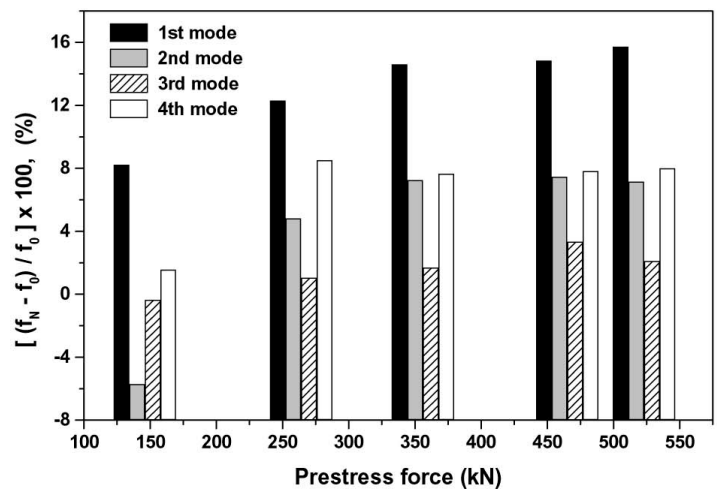

(b) SIMO sine sweep test

Fig. 8. Change Rate of Natural Frequency in Accordance with Prestress Force 
difference in natural frequency at a different level of prestress force with a prestress force of $0 \mathrm{kN}$ as the base. $\mathrm{f}_{\mathrm{N}}$ is the natural frequency at five prestress forces from $146 \mathrm{kN}$ to $523 \mathrm{kN}$ and $\mathrm{f}_{0}$ is the natural frequency at $0 \mathrm{kN}$. As shown in Fig. 8, the change rate of the $1^{\text {st }}$ modal natural frequency is the largest compared with the change rates of the other natural frequencies. The large change rate of the natural frequency indicates great sensitivity to prestress force. Therefore, the possibility is confirmed that the prestress force of a bonded tendon can be predicted with the SI technique using natural frequency, since variation in natural frequency occurs due to changes in prestress force. In particular, the natural frequency of the lower mode has a high correlation with prestress force as shown in Fig. 8, and the $1^{\text {st }}$ modal natural frequency is the best for predicting the prestress force of a bonded tendon. Also, the natural frequencies of the SIMO sine sweep test are more consistent than the impact test to prestress force and the SIMO sine sweep test is recommended to predict the prestress force of a bonded tendon.

\subsection{Bending Test}

\subsubsection{Optical Fiber Sensor}

In order to analyze the reliability of the displacements measured by optical fiber sensors, the difference between the displacements measured by the two sets of optical fiber sensors installed on the scale-model specimen were compared as shown in Fig. 9. $\delta_{1-n}$ is the displacement measured by the optical fiber sensor on the right side and $\delta_{2-n}$ is the displacement measured by the optical fiber sensor on the left side in Fig. 3. Except for the four displacements measured at $264 \mathrm{kN}$ and $356 \mathrm{kN}$, all displacements showed similar results with difference ratios less than $10 \%$ as presented in Fig. 9, indicating that the measured displacements are highly reliable.

Figure 10 illustrates displacements according to the

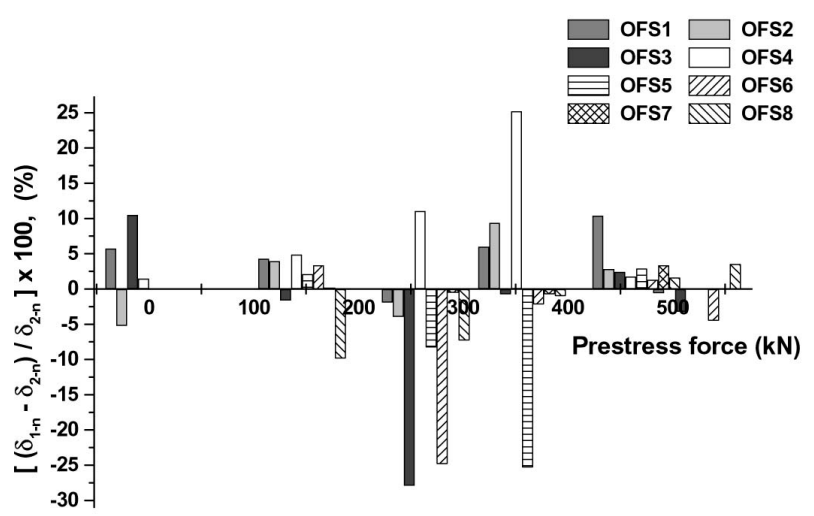

Fig. 9. Comparison of Displacements Measured by Optical Fiber Sensors prestress forces at each optical fiber sensor. As shown in Fig. 10, displacements decreased inversely to the magnitude of the prestress force. Therefore, the possibility was verified that the prestress force of a bonded tendon can be predicted using displacement, since the change in displacement occurs due to prestress force. Figure 11 shows the change rate of displacement according to prestress force at each optical fiber sensor. $\delta_{N}$ is the displacement at five prestress forces from $146 \mathrm{kN}$ to 523 $\mathrm{kN}$ and $\delta_{0}$ is the displacement at $0 \mathrm{kN}$. As shown in Fig. 11 , optical fiber sensor Nos. 4 and 5, at which occurs the largest displacement, shows a consistently increasing trend in prestress force, while optical fiber sensor Nos. 1 and 8 , at which occurs the smallest displacement, shows an inconsistent trend in prestress force. Therefore, when predicting prestress force using an optical fiber sensor, these sensors should be installed at locations where large displacement occurs.

\subsubsection{Compact Displacement Transducer}

Figure 12 shows displacement as measured by the compact displacement transducer according to prestress forces. As shown in Fig. 12, the correlation between displacement by the compact displacement transducer and prestress force is almost the same as that for the optical fiber sensor. This indicates that a compact displacement transducer can be used to predict the prestress force of a bonded tendon. Figure 13 shows the change rate of displacement according to prestress force at each compact displacement transducer. The definition of $\delta_{N}$ and $\delta_{0}$ is the same as in Fig. 11. As shown in Fig. 13, the change rate of the displacement by each compact displacement transducer is almost the same at each prestress force. Therefore, when predicting prestress force using a compact displacement transducer, the installed location of the compact displacement transducer is not important.

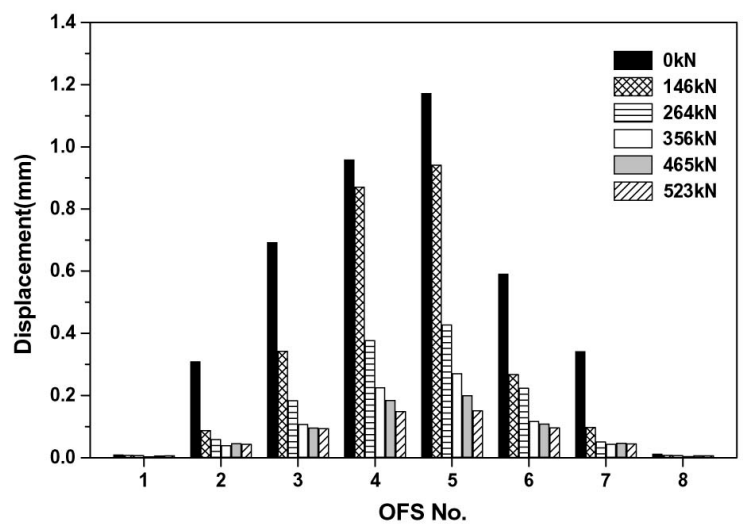

Fig. 10. Displacement by Optical Fiber Sensor vs. Prestress Force 


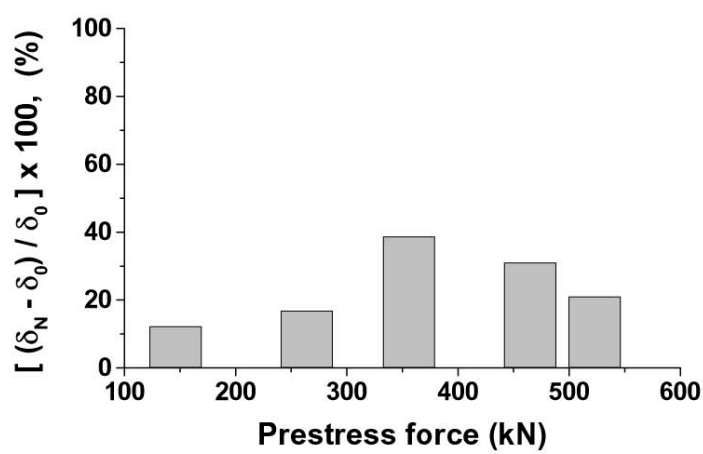

(a) OFS 1

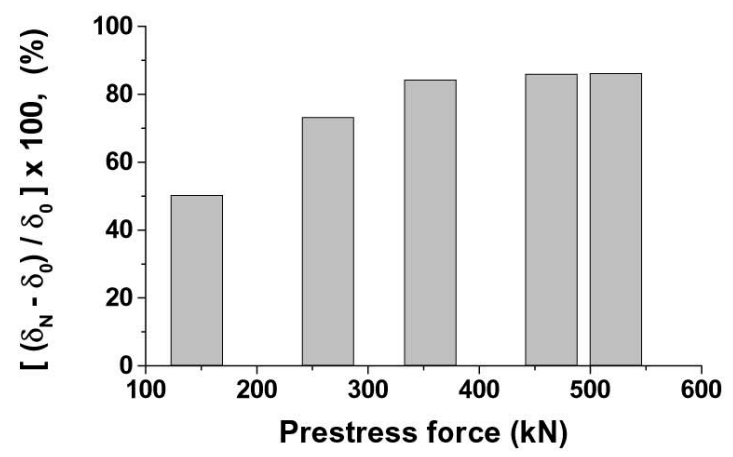

(c) OFS 3

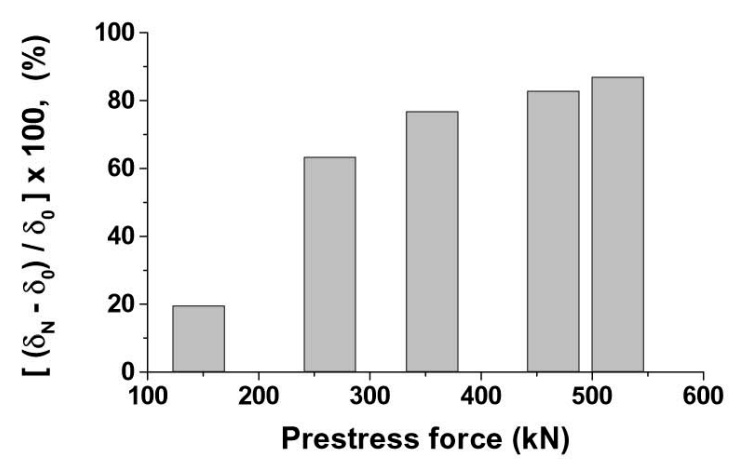

(e) OFS 5

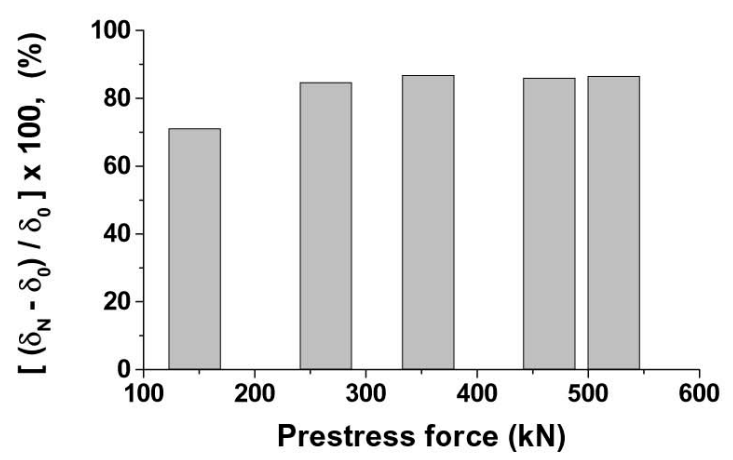

(g) OFS 7

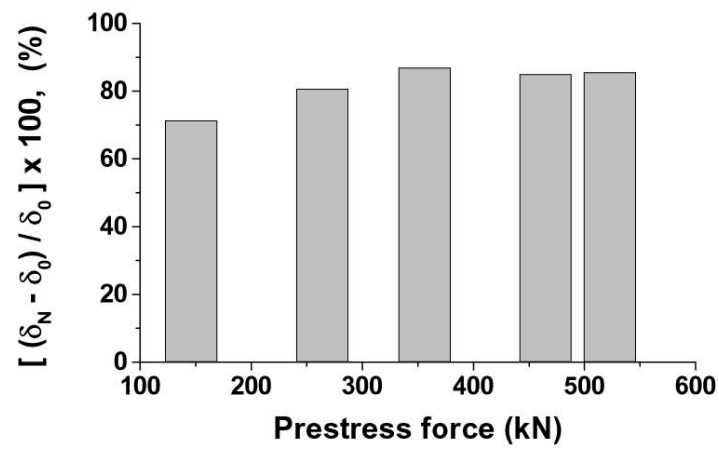

(b) OFS 2

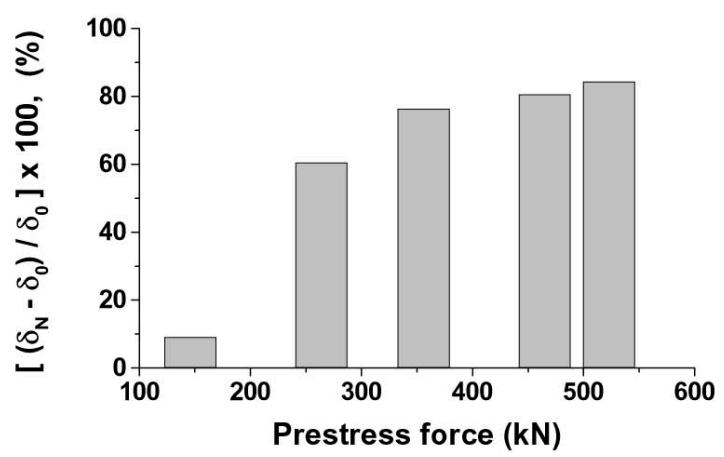

(d) OFS 4

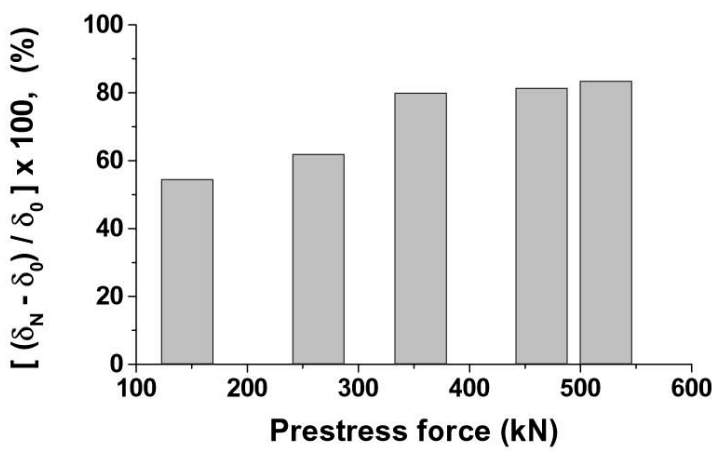

(f) OFS 6

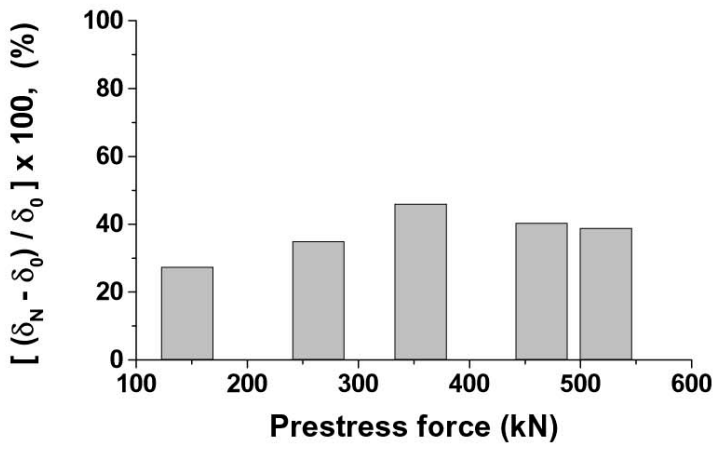

(h) OFS 8

Fig. 11. Change Rate of Displacement vs. Prestress Force 


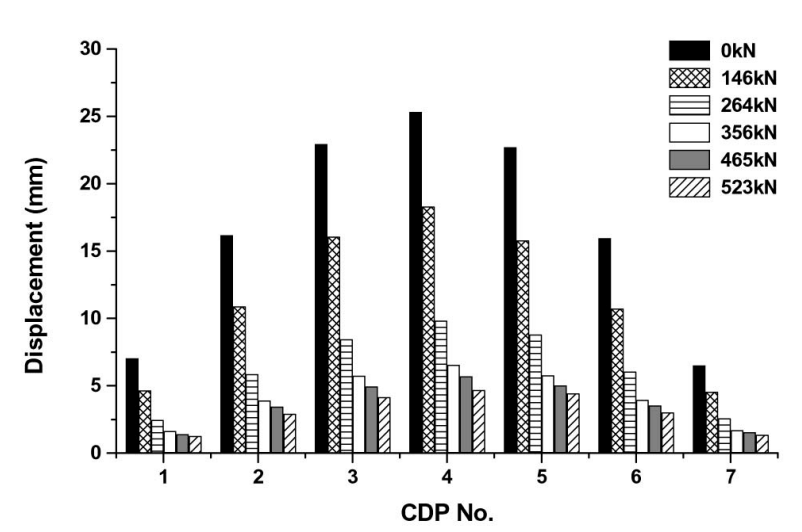

Fig. 12. Displacement by Compact Displacement Transducer in Accordance with Prestress Force

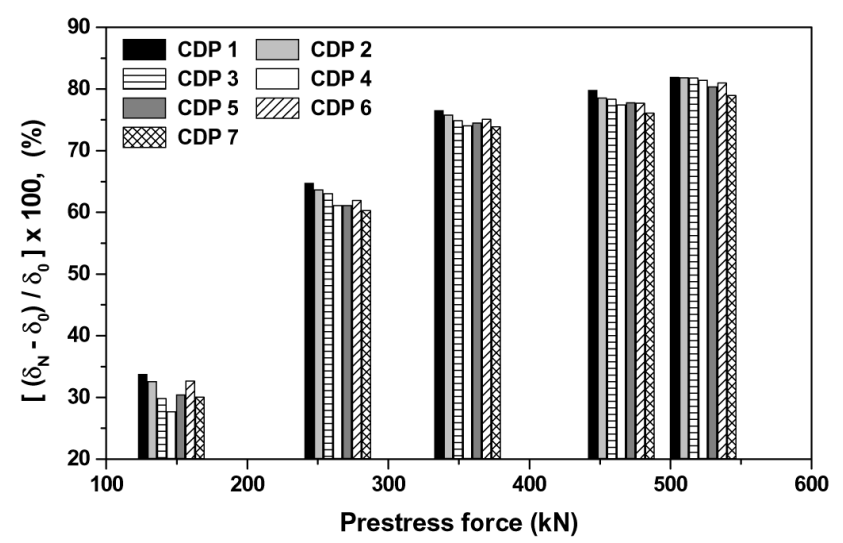

Fig. 13. Change Rate of Displacement in Accordance with Prestress Force

Table 1. Change Rate of Each Parameter to Prestress Force

\begin{tabular}{c|c|c|c|c|c|c}
\hline \multirow{2}{*}{$\begin{array}{c}\text { Prestress force } \\
(\mathrm{kN})\end{array}$} & \multicolumn{2}{|c|}{ Natural frequency } & \multicolumn{2}{c|}{ Displacement of OFS } & \multicolumn{2}{c}{ Displacement of CDP } \\
\cline { 2 - 7 } & Magnitude(Hz) & Change rate (\%) & Magnitude(mm) & Change rate (\%) & Magnitude(mm) & Change rate $(\%)$ \\
\hline 0 & 7.567 & 0.0 & 0.959 & 0.0 & 25.33 & 0.0 \\
\hline 146 & 8.190 & 8.2 & 0.872 & 9.1 & 18.31 & 27.7 \\
\hline 264 & 8.498 & 12.3 & 0.379 & 60.5 & 7.84 & 6.56 \\
\hline 356 & 8.672 & 14.6 & 0.227 & 76.4 & 5.70 & 77.5 \\
\hline 465 & 8.690 & 14.8 & 0.186 & 80.7 & 4.69 & 81.5 \\
\hline 523 & 8.757 & 15.7 & 0.150 & 84.4 & & \\
\hline
\end{tabular}

\section{OPTIMAL PARAMETERS}

Both natural frequency and displacement change according to the magnitude of prestress force and show a good correlation as illustrated through modal and bending tests. Therefore, it was concluded that the prediction of prestress force of a bonded tendon is possible with these parameters using the SI technique. However, when predicting the prestress force of a bonded tendon using the SI technique, it is advisable to use the parameter that has a high correlation with prestress force-in other words, the parameter with the largest change rate according to the prestress force level for the input data of the SI technique.

Thus, measured data that show a consistency and a high correlation with prestress force, were chosen from the above test results to select the best parameters for predicting the prestress force of a bonded tendon. That is, the SIMO sine sweep test that provides consistent measured results with the prestress force was selected out of the impact test and the SIMO sine sweep test for the modal test. In addition, the natural frequencies of the $1^{\text {st }}$ mode are presented in Table 1, which shows the highest correlation among the $1^{\text {st }}$ to the $4^{\text {th }}$ natural frequencies.

Furthermore, for the bending test using optical fiber sensors, measured data of the number 4 sensor were input into Table 1, which show the most consistent results for prestress force out of the eight optical fiber sensors. Lastly, for the bending test using a compact displacement transducer, measured data of the centered displacement transducer were put into Table 1, which were selected under the same criteria as for the optical fiber sensor. The change rate in Table 1 indicates the rate of change for each parameter according to the different levels of prestress force.

Figure 14 illustrates the results of Table 1 . The change rates of both the optical fiber sensor and the compact displacement transducer at different prestress force levels were extremely large compared to that of the natural frequency. Moreover, the change rates of the optical fiber 


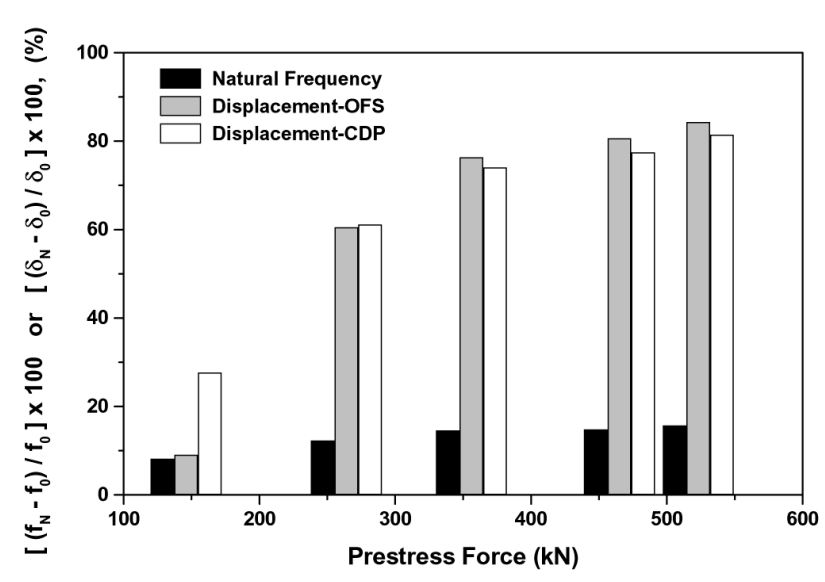

Fig. 14. Correlation Between Prestress Force and Each Parameter

sensor and the compact displacement transducer were almost the same except at $146 \mathrm{kN}$. However, when considering that optical fiber sensor Nos. 4 and 5 generate the same test results as shown in Fig. 3, and also the fact that the change rate of the number 5 optical fiber sensor is $19.6 \%$ as in Fig. 11, it can be concluded that the optical fiber sensor and the compact displacement transducer have a similar level of correlation with prestress force.

The displacements of the optical fiber sensor and the compact displacement transducer show a higher correlation with prestress force compared to the natural frequency as indicated in Fig. 14. When using the SI technique to assess the prestress force of the bonded tendon, it is thus advisable to use these displacements.

\section{CONCLUSION}

Bonded tendons have been installed in reactor buildings in heavy water reactors and light water reactors of some nuclear power plants operating in Korea and the assessment of the prestress force on these bonded tendons is becoming an important issue in efforts to assure continued operation beyond their design life. This study proposes a technique to assess prestress force on bonded tendons using the SI technique. As a first step, the study evaluated the influence of parameters important to the SI technique when assessing prestress force and derived the optimal parameters.

For this study, a total of six scale-model specimens with bonded tendons were manufactured in order to analyze the correlation between the natural frequency and the displacement and the prestress force of a bonded tendon. A modal test and bending tests were also carried out. An impact test and a SIMO sine sweep test were performed as the modal test for the natural frequency and the bending tests using the optical fiber sensor and the compact displacement transducer were carried out for the displacement.

The test results showed that both natural frequency and displacement change according to the magnitude of prestress force and have a good correlation with prestress force. Thus, it was confirmed that the prestress force of a bonded tendon can be predicted reliably when these parameters are used as input data for the SI technique. However, as the displacement of the optical fiber sensor and the compact displacement transducer have a higher correlation with prestress force as compared to natural frequency, it is advisable to use these displacements when using the SI technique to assess the prestress force of a bonded tendon.

\section{ACKNOWLEDGMENTS}

This paper was conducted as a nuclear power technology innovation project with the generous support of the Korean Ministry of Knowledge Economy. We greatly appreciate their support.

\section{REFERENCES}

[1] Ministry of Commerce and Industry, Development of the Next Generation's Nuclear Reactor Technology (I) Final report (1994).

[2] Korea Hydro \& Nuclear Power Co., Ltd., Research on Wolseong Number 1 Lifetime Management (II), Intermediate report (2006).

[3] NCHRP, Nondestructive Methods for Condition Evaluation of Prestressing Steel Strands in Concrete Bridges, Final report (1999).

[4] Unger, J. F., Teughels, A. and Roeck, G. D., "System Identification and Damage Detection of a Prestressed Concrete Beam", Journal of Structural Engineering, ASCE, pp. 1691 - 1698 (2006).

[5] Maaskant, R., Alavie, T., Measures, R., Tadros, G., Rizkalla, S., and Guha-Thakurta, A., "Fibre-optic Bragg Grating Sensors for Bridge Monitoring", Cem. Concr. Compos. 19, pp. 21-23 (1997).

[6] Kim, J. T., Ryu, Y. S., Cho, H. M., and Stubbs, N., "Damage Identification in Beam-Type Structures : Frequency - Based Method vs Mode - Shape - Based Method”, Engineering Structures 25, pp. 57 - 67 (2003).

[7] Law, S. S. and Lu, Z. R., "Time Domain Responses of a Prestressed Beam and Prestress Identification", Journal of Sound and Vibration, pp. 1011 - 1025 (2005).

[ 8 ] Saiidi, N., Douglas, B., Feng, S., "Prestress Force Effect on Vibration Frequency of Concrete Bridges", Journal of Structural Engineering 120(7), pp. 2233 - 2241 (1994).

[9] Abraham, M. A., Park, S. Y., Stubbs, N., "Loss of Prestress Prediction on Nondestructive Damage Location Algorithms, SPIE", Smart Structures and Materials 2446, pp. $60-67$ (1995).

[10] Hamed, E., Frostig, Y., "Natural Frequencies of Bonded and Unbonded Prestressed Beam-Prestress Force Effects", Journal of Sound and Vibration 295, pp. 28 - 39 (2006). 
[11] Lu, Z. R., Law, S. S., "Identification of Prestress Force from Measured Structural Responses", Mechanical Systems and Signal Processing 20, pp. $2186-2199$ (2005).
[12] Ministry of Commerce, Industry and Energy, Deformation Characteristics and Measurement Technology using Optical Fiber for Nuclear Power Plant Containment Buildings, Final report (2005). 